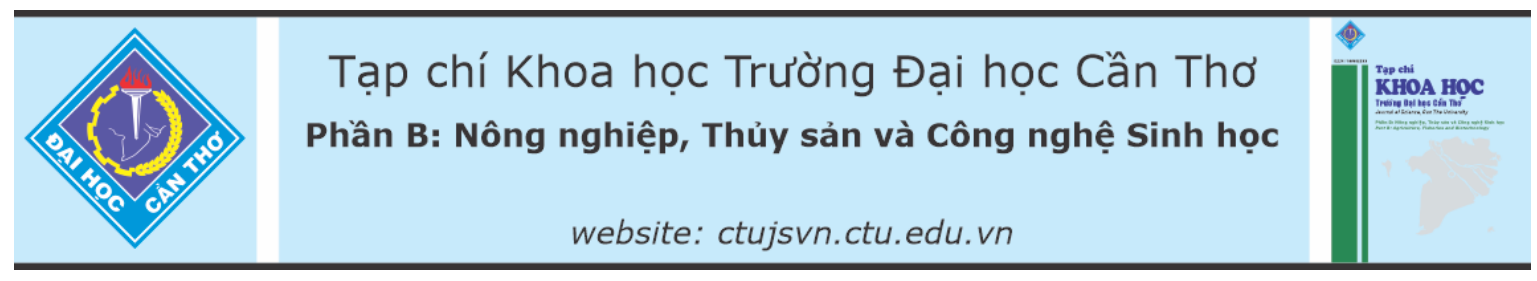

DOI:10.22144/ctu.jvn.2021.183

\title{
NGHÊN CÚU GIẢM ĐẮNG NƯỚC BƯỞI THANH TRÙNG BĂNG CHẾ PHẨM ENZYME BIOCITRUS
}

\author{
Hoàng Quang Bình ${ }^{1,2}$, Trần Thị $\mathrm{Ny}^{1}$, Huỳnh Tiến Đạt ${ }^{1}$, Lê Trung Thiên ${ }^{1,2^{*}}$ \\ ${ }^{1}$ Khoa Công nghệ Thưc phẩm, Truờng Đại học Nông Lâm Thành phố Hồ Chi Minh \\ ${ }^{2}$ Công ty TNHH Lê Trung Thiên \\ *Người chịu trách nhiệm về bài viết: Lê Trung Thiên (email: le.trungthien@hcmuaf.edu.vn)
}

\section{Thông tin chung:}

Ngày nhận bài: $27 / 05 / 2021$

Ngày nhận bài sủa: 30/09/2021

Ngày duyệt đăng: 25/12/2021

Title:

Effect of Biocitrus enzymatic treatment on the bitter taste of the pomelo juice

\section{Tù khóa:}

Enzyme Biocitrus, giảm đắng, naringin, nước buởi

\section{Keywords:}

Enzyme Biocitrus, naringin, pomelo juice, reduce bitter

\begin{abstract}
Pomelo had beneficial compounds such as vitamin C, polyphenols. However, pomelo juice often had an unpleasant bitter taste after pasteurizing. This study was conducted to evaluate the ability to reduce the bitterness of pomelo juice by enzymatic treatment with enzyme Biocitrus. Factors such as $\mathrm{pH}$ (pH natural (3.5-3.6), 4.5, 5.5 and 6.5), hydrolysis temperature (room temperature $(29-31), 40,50$ and $60^{\circ} \mathrm{C}$ ) and hydrolysis period $(0.5,1.0,2.0$ and $3.0 \mathrm{~h})$ were evaluated in this study, respectively. The compounds like naringin, polyphenols, and vitamin $C$ were quantified by spectrophotometer; moreover, the bitter taste was evaluated sensory by scoring test. The results showed that the suitable parameter includes the temperature of $60^{\circ} \mathrm{C}$, the $\mathrm{pH}$ of the juice was 4.5, and the hydrolysis period of 2 hours. Under these conditions, the pasteurized pomelo juice reduced remarkably bitter taste. Besides, the sample had naringin content lower than the control sample, meanwhile, the phenolic and vitamin $C$ contents of both samples were slightly different.
\end{abstract}

\section{TÓM TẮT}

Bưởi có nhiều hợp chất có lợi cho sức khỏe nhu vitamin C, polyphenol. Nuớc bưởi sau thanh trùng thuờng có vị đắng khó chịu. Nghiên cứu này được thực hiện nhằm đánh giá khả năng cải thiện vị đắng của nuớc buởi sau thanh trùng bằng phưong pháp thủy phân với chế phẩm enzyme Biocitrus. Các yếu tố nhu pH (pH tự nhiên (3,5-3,6), 4,5, 5,5 và 6,5), nhiệt độ thủy phân (nhiệt độ phòng $\left(29-31^{\circ} \mathrm{C}\right), 40^{\circ} \mathrm{C}, 50^{\circ} \mathrm{C}$ và $\left.60^{\circ} \mathrm{C}\right)$ và thò̀ gian thủy phân (0,5, 1,0, 2,0 và 3,0 giơ) lần luợt được thưc hiện. Các hơp chất nhu naringin, polyphenol và vitamin $C$ trong nuớc buơoi được dịnh luợng bằng máy đo quang phổ UV-VIS, bên cạnh đó vị đắng của nước buơơi cũng đurợc đánh giá cảm quan bằng phép thư cho điểm. Kết quả cho thấy thủy phân dịch bười tại nhiệt độ $60^{\circ} \mathrm{C}, \mathrm{pH}$ môi trường 4,5 và thời gian thủy phân trong 2 giờ cho nuớc buởi sau thanh trùng có vị đắng giảm so với nước bưởi không xử lý. Nưóc bươi xủ lý enzyme sau thanh trùng có hàm lượng naringin thấp hơn 2 lần so với nước bưởi không xủ lý, giũa hai sản phẩm khác biệt về hàm lương polyphenol và vitamin $C$. Enzyme Biocitrus có nhiều triển vọng trong ứng dụng giảm đắng của nước buơoi thanh trùng. 


\section{1. ĐẶT VẤN ĐỀ}

Bên cạnh những thành phần hóa học như polysaccharide, khoáng, acid hữu cơ, trong quả bưởi còn chứa nhiều hợp chất kháng oxy hóa tốt cho sức khỏe (Cheong et al., 2012; Toh et al., 2013; Xu et al., 2008). Thị trường trong nước đã xuất hiện sản phẩm nước ép bưởi và được nhiều người tiêu dùng yêu thích. Tuy nhiên, sản phẩm này dễ bị lên men, do đó có thời gian sử dụng ngắn ngày. Thanh trùng là phương pháp phổ biến được ứng dụng trong hạn chế hiện tượng lên men không mong muốn trong các sản phẩm đồ uống. Tuy nhiên, nước bưởi sau thanh trùng thường có vị đắng khó chịu, ít được nhiều tiêu dùng chấp nhận. Sử dụng enzyme đã có hiệu quả tốt trong giảm vị đắng nước bưởi chùm (BodakowskaBoczniewicz et al., 2019; Prakash et al., 2002) và nước cam (De Silva et al., 2017). Tuy nhiên, giống bưởi chùm hiện không được trồng phổ biến tại Việt Nam, trong khi đó các giống bưởi thông dụng trong nước như bưởi năm roi, bưởi da xanh, bưởi tân triều,... hiện trong nước vẫn còn ít công trình công bố về khả năng áp dụng enzyme trong giảm đắng nước bưởi.
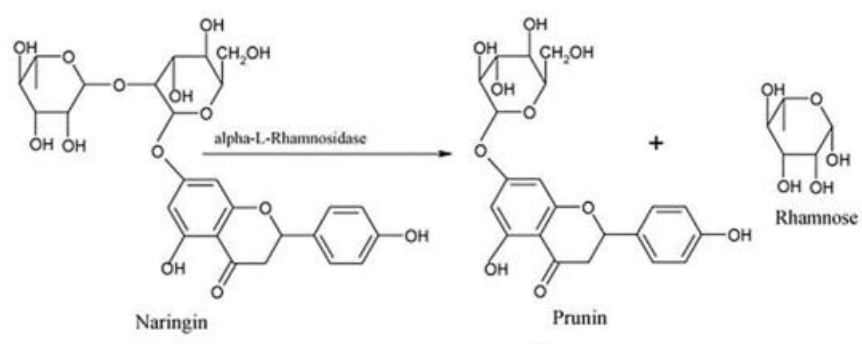

(a)

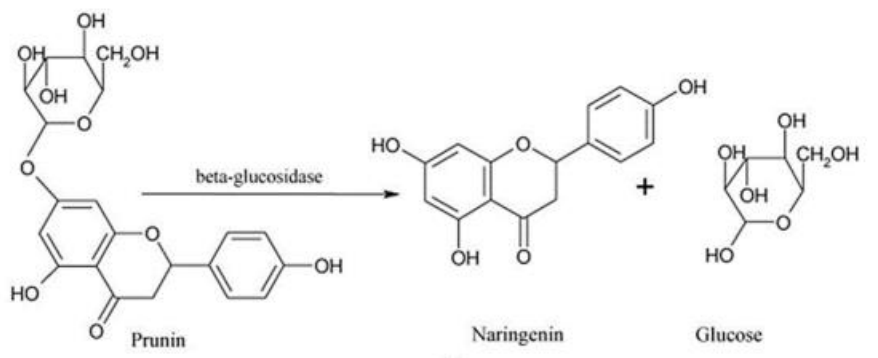

Hình 1. Sơ đồ chuyển đổi của naringin dưới tác động của enzyme Biocitrus

(Yadav et al., 2010)

\section{PHƯƠNG PHÁP NGHIÊN CÚU}

\subsection{Nguyên liệu và hóa chất}

Buơi năm roi (Citrus grandis cv. 'Nam Roi') được mua từ chợ Đầu mối Nông sản Thủ Đức, Thành phố Hồ Chí Minh. Nguyên liệu được lựa chọn là những trái không bị hư, thối hỏng. Trọng lượng trung bình khoảng $750 \mathrm{~g}$ /quả. Dịch quả có
Naringin là một trong những hợp chất chính tạo vị đắng trong nước ép quả có múi (Patil \& Dhake, 2014; Ribeiro \& Ribeiro, 2008). Trong các xuất bản khoa học đã công bố ở nước ngoài, enzyme naringinase là loại enzyme được sử dụng chủ yếu trong giảm đắng nước quả họ cây có múi. Tuy nhiên, đây là loại enzyme có độ tỉnh khiết cao, giá thành khá mắc chưa phù hợp cho sản xuất thực tiễn. Dựa trên thông tin cung cấp từ công ty sản xuất enzyme, Biocitrus là chế phẩm enzyme thương mại có khả năng tốt trong giảm đắng nước ép của các họ cây có múi. Chế phẩm emzyme Biocitrus chứa chủ yếu hai enzyme gồm $\beta$-glucosidase và $\alpha$-rhamnosidase. Dưới tác động của các enzyme này, naringin bị chuyển đổi thành naringenin, một hợp chất có vị ít đắng hơn (Hình 1). Các nghiên cứu trước đã chỉ ra rằng $\mathrm{pH}$, nhiệt độ, thời gian là một trong những yếu tố quyết định đến khả năng hoạt động của enzyme (Bodakowska-Boczniewicz et al. 2019; Prakash et al., 2002). Nghiên cứu này được thực hiện nhằm tìm ra điều kiện thủy phân $(\mathrm{pH}$, nhiệt độ và thời gian thủy phân) thích hợp cho enzyme Biocitrus. 
nghiên cứu này, bưởi năm roi đã được chọn làm đối tượng sử dụng.

Chế phẩm enzyme Biocitrus được sản xuất bởi công ty BIOCON (Tây Ban Nha) và phân phối bởi công ty CTC (Việt Nam). Enzyme được sản xuất từ nấm mốc Penicillium sp., có hoạt tính $\geq 1600$ UB/g ( $\mu$ mol $\mathrm{p}$-nitrofenol cho một phút tại $\mathrm{pH} 5$ và nhiệt độ $40^{\circ} \mathrm{C}$ ), nhiệt độ hoạt động tối ưu $60-70^{\circ} \mathrm{C}, \mathrm{pH}$ tối ưu 4,5-5,0. Chế phẩm enzyme chứa đa số enyzme $\beta$ glucosidase và $\alpha$-rhamnosidase.

Hóa chất: Folin Ciocalteu 99,5\%, DPPH (EMD Millipore - Đức), ethanol 99,6\% (Chemsol - Việt Nam). Methanol 99,5\%, $\mathrm{NaOH} 96,0 \%, \mathrm{Na}_{2} \mathrm{CO}_{3}$ $99,5 \%$, thiourea, ascorbic acid $99,5 \%$, gallic acid 99,5\%, metaphosphoric acid, acetic acid, bromine $3 \%$, 2,4-DNPH, $\mathrm{H}_{2} \mathrm{SO}_{4} 98 \%$, trichloroacetic acid, HCl $35-38 \%$ (Xilong, Trung Quốc).

Thiết bị: máy đo quang phổ (UV-VIS V730 Nhật Bản), cân điện tử 2 số lẻ (N92, A\&amp; D Hàn Quốc), khúc xạ kế 0-100 (Atago, Nhật Bản), bể điều nhiệt (WNB 14, Memmert - Đức), máy đồng hóa (IKA T25 Ultra-turrax).

\subsection{Quy trình chuẩn bị mẫu}

Bưởi sau khi thu mua được rửa sạch, bỏ vỏ, loại hạt và được ép dịch quả. Dịch ép bưởi được giũ̃ trong cốc thủy tinh $250 \mathrm{~mL}$ và được hiệu chỉnh $\mathrm{pH}$ bằng dung dịch $\mathrm{NaHCO}_{3}(\mathrm{pH} 9,0)$. Tiếp theo, mẫu được nâng nhiệt từ nhiệt độ phòng $\left(29-31^{\circ} \mathrm{C}\right)$ đến $60^{\circ} \mathrm{C}$ bằng bể ổn định nhiệt. Khi nhiệt độ tâm của dịch quả đạt nhiệt độ khảo sát $60^{\circ} \mathrm{C}$, enzyme Biocitrus được bổ sung vào dịch quả với tỷ lệ $0,1 \%$ $(\mathrm{g} / 100 \mathrm{~mL})$ và thủy phân trong 1 giờ. Kết thúc quá trình thủy giải, enzyme được bât hoạt ở $90^{\circ} \mathrm{C} / 5$ phút bằng bể ổn định nhiệt. Nước bưởi sau đó được làm nguội nhanh bằng nước và được hiệu chỉnh về $\mathrm{pH}$ 4,0 bằng dung dịch citric acid $20 \%$. Tiếp theo, mẫu được thanh trùng tại $85^{\circ} \mathrm{C}$ trong 10 phút. Nước quả sau khi làm nguội bằng nước được tiến hành phân tích các chỉ số hóa học và cảm quan trong ngày.

\section{Bố trí thí nghiệm}

\subsubsection{Anh hương của $p H$ đến khả năng hoạt động của chế phẩm enzyme}

Thí nghiệm 1 yếu tố là $\mathrm{pH}$ nước ép bưởi gồm 4 mức: $\mathrm{pH}$ tự nhiên $(3,5-3,6), 4,5,5,5$ và 6,5 . Nước bưởi sau khi hiệu chỉnh $\mathrm{pH}$ theo bố trí thí nghiệm được tiến hành thủy phân theo các thông số đã được trình bày trong mục 2.2. Mẫu sau khi thủy phân, thanh trùng và làm nguội được phân tích các chỉ tiêu gồm: hàm lượng naringin, vitamin $\mathrm{C}$, polyphenol tổng và đánh giá cảm quan. Thí nghiệm được lặp lại 3 lần.

\subsubsection{Anh hưởng của nhiệt độ đến khả năng hoạt động của chế phẩm enzyme}

Thí nghiệm 1 yếu tố là nhiệt độ thủy phân gồm 4 mức: nhiệt độ phòng $\left(29-31^{\circ} \mathrm{C}\right), 40^{\circ} \mathrm{C}, 50^{\circ} \mathrm{C}$ và $60^{\circ} \mathrm{C}$. Nước ép bưởi sau khi được hiệu chỉnh $\mathrm{pH}$ theo kết quả của thí nghiệm mục 2.2.1, mẫu được tiến hành thủy phân theo các thông số đã được trình bày trong mục 2.2 ; trong đó nhiệt độ thủy phân được thực hiện theo bố trí thí nghiệm, các thông số còn lại được cố định. Mẫu sau khi thủy phân, thanh trùng và làm nguội được phân tích các chỉ tiêu gồm: hàm lượng naringin, vitamin $\mathrm{C}$, polyphenol tổng và đánh giá cảm quan. Thí nghiệm được lặp lại 3 lần.

\subsubsection{Anh hưởng thời gian thủy phân đến khả năng hoạt động của chê phẩm enzyme}

Thí nghiệm 1 yếu tố là thời gian thủy phân gồm 4 mức: $0,5,1,0,2,0$ và 3,0 giờ. Nước ép bưởi sau khi được hiệu chỉnh $\mathrm{pH}$ theo kết quả của thí nghiệm mục 2.2.1, mẫu được tiến hành thủy phân theo các thông số đã được trình bày trong mục 2.2. Trong đó, nhiệt độ thủy phân được tham chiếu theo kết quả thí nghiệm mục 2.2.2, các thông số còn lại được cố định. Mẫu sau khi thủy phân, thanh trùng và làm nguội được phân tích các chỉ tiêu gồm: hàm lượng naringin, vitamin $\mathrm{C}$, polyphenol tổng và đánh giá cảm quan. Thí nghiệm được lặp lại 3 lần.

\subsubsection{So sánh thành phần hóa hoc và vị đắng của mẫu có và không xủ lý enzyme}

Mẫu nước bưởi xử lý giảm đắng: Trong một cốc thủy tinh, $200 \mathrm{~mL}$ nước ép bưởi được hiệu chỉnh pH bằng dung dịch $\mathrm{NaHCO}_{3}(\mathrm{pH} 9,0)$. Khi $\mathrm{pH}$ nước bưởi đạt 4,5, mẫu được nâng nhiệt độ từ $29-31^{\circ} \mathrm{C}$ đến $60^{\circ} \mathrm{C}$ bằng bể ổn định nhiệt. Tiếp theo, enzyme Biocitrus được bổ sung vào trong nước bưởi theo tỷ lệ $0,1 \%(\mathrm{~g} / 100 \mathrm{~mL})$. Sau 2 giờ thủy phân tại nhiệt độ $60^{\circ} \mathrm{C}$, mẫu được rót vào chai thủy tinh và thanh trùng tại $85^{\circ} \mathrm{C}$ trong 10 phút. Nước quả sau khi làm nguội bằng nước được phân tích hàm lượng naringin, vitamin $\mathrm{C}$, polyphenol tổng và đánh giá cảm quan. Thí nghiệm được lặp lại 3 lần.

Mẫu nước bưởi không xử lý giảm đắng. Dịch ép nước bưởi $(200 \mathrm{~mL})$ được hiệu chỉnh về $\mathrm{pH} 4,5$ bằng dung dịch $\mathrm{NaHCO}_{3}(\mathrm{pH} 9,0)$. Tiếp theo, mẫu được rót chai thanh trùng tại nhiệt độ $85^{\circ} \mathrm{C}$ trong 10 phút và được làm nguội nhanh bằng nước. Mẫu thí nghiệm được phân tích các chỉ tiêu: hàm lượng naringin, hàm lượng vitamin $\mathrm{C}$, hàm lượng polyphenol tổng và đánh giá cảm quan. 


\subsection{Phương pháp phân tích}

Hàm lương Naringin: Phương pháp phân tích được tham chiếu theo Davis (1947). Micropipet được sử dụng để chuyển $0,2 \mathrm{~mL}$ mẫu cho vào bình định mức $10 \mathrm{~mL}$, tiếp tục $0,2 \mathrm{~mL} \mathrm{NaOH} 4 \mathrm{M}$ được cho vào bình định mức và lắc đều. Sau đó, ethylene glycol được sử dụng để định mức dung dịch lên 10 mL. Mẫu được để yên trong tối ở nhiệt độ phòng $(29$ $-31^{\circ} \mathrm{C}$ ) trong 15 phút; sau đó, mẫu được đo độ hấp thụ quang phổ ở bước sóng $420 \mathrm{~nm}$. Dựa vào phương trình đường chuẩn naringin, hàm lượng naringin được thể hiện theo mg NE/100g mẫu.

Hàm luợng vitamin $C$ : Phương pháp phân tích được tham chiếu theo Kapur et al. (2012). Một mL dịch mẫu được cho vào trong ống nghiệm; sau đó $230 \mu \mathrm{L}$ bromie $3 \%, 130 \mu \mathrm{L}$ thiourea $10 \%$ và $1 \mathrm{~mL}$ hỗn hợp dung dịch 2,4 DNPH lần lượt được cho vào ống nghiệm. Mẫu được lắc đều và đem đi ủ ở $37^{\circ} \mathrm{C}$ trong 3 giờ. Sau đó, mẫu được thêm $5 \mathrm{~mL} \mathrm{H}_{2} \mathrm{SO}_{4}$ $85 \%$ và lắc đều; phản ứng diễn ra trong điều kiện chắn sáng. Sau 30 phút, mẫu được xác định độ hấp thụ quang phổ ở bước sóng $521 \mathrm{~nm}$. Dựa vào phương trình đường chuẩn ascorbic acid, hàm lượng vitamin $\mathrm{C}$ được thể hiện theo $\mathrm{mg} \mathrm{AAE} / 100 \mathrm{~g}$ mẫu.

Hàm lương polyphenol tổng: Phương pháp phân tích được tham chiêu theo Lim et al. (2007). Trong ống nghiệm, $0,5 \mathrm{~mL}$ dịch trích được trộn đều với 2,5 $\mathrm{mL}$ Folin-Ciocalteu $10 \%$ và để yên trong tối khoảng 5 phút. Sau đó, $2 \mathrm{~mL} \mathrm{Na}_{2} \mathrm{CO}_{3} 7,5 \%$ được cho vào ông nghiệm và lắc đều. Sau 60 phút mẫu được xác định độ hấp thụ quang phổ ở bước sóng $765 \mathrm{~nm}$. Dựa vào phương trình đường chuẩn gallic acid, hàm lượng polyphenol tổng được thể hiện theo $\mathrm{mg}$ GAE/100 g mẫu.

Đánh giá cảm quan: $20 \mathrm{~mL}$ mẫu được đựng trong ly thủy tinh. Mẫu được mã hóa bằng số 3 chữ số. Mẫu được đánh giá bởi 20 cảm quan viên là các sinh viên, các cảm quan viên không sử dụng bất kì thực phẩm nào trước 30 phút thử mẫu. Sau mỗi lần thử mẫu, người đánh giá sử dụng nước lọc để thanh vị. Mẫu được đánh giá về cường độ vị đắng với thang điểm 9 , trong đó 1 : không đắng và 9 : rất đắng (Hà Duyên Tư, 2010).

\subsection{Phương pháp xử lý số liệu}

Các thí nghiệm được lặp lại 3 lần, các kết quả được thể hiện dưới dạng trung bình \pm độ lệch chuẩn. Các số liệu thu thập được tính toán, vẽ đồ thị bằng Excel 2013. Các phân tích phương sai (ANOVA) được thực hiện, sự khác biệt về mặt thống kê của các kết quả được xử lý bằng phần mềm JMP 13.0 tại $\mathrm{p}<$ 0,05 .

\section{KẾT QUẢ VÀ THẢO LUẬN}

\section{1. Ảnh hưởng của pH đến khả năng hoạt động của chế phẩm enzyme}

Kết quả thực nghiệm thể hiện trong Hình 2 cho thấy khi $\mathrm{pH}$ môi trường đạt 4,5 , mẫu có hàm lượng naringin thấp nhất $3,94 \mathrm{mg} / 100 \mathrm{~mL}$; trong khi đó, $\mathrm{pH}$ tăng từ 5,5-6,5 dẫn đến mẫu có hàm lượng naringin cao $4,77-6,54 \mathrm{mg} / 100 \mathrm{~mL}$. Sau quá trình xử lý enzyme, các mẫu có $\mathrm{pH}$ cao thì có hàm lượng naringin cao. Chế phẩm enzyme Biocitrus chủ yếu chứa $\beta$-Glucosidase and $\alpha$-Rhamnosidase, hai loại enzyme này có khả năng phân cắt naringin; đây là nguyên nhân dẫn đến hàm lượng naringin. Theo thông tin cung cấp từ nhà sản xuất, chế phẩm enzyme hoạt động tốt ở pH khoảng 4,5, do đó dịch bưởi được hiệu chỉnh $\mathrm{pH}$ đến khoảng giá trị này đã tạo điều kiện cho enzyme hoạt động mạnh hơn so với mức $\mathrm{pH}$ còn lại.

Hàm lượng polyphenol tổng và vitamin $\mathrm{C}$ giữa các mẫu có sự thay đổi dưới tác động của điều kiện $\mathrm{pH}$ môi trường khác nhau, hàm lượng polyphenol tổng ghi nhận được ở tất các nghiệm thức nằm trong khoảng 86,10-90,12 mgGAE/100mL; hàm lượng vitamin $C$ của mẫu có giá trị từ 45,36 đến 47,70 mgAAE $/ 100 \mathrm{~mL}$. Phân tích thống kê cho thấy giữa các mẫu có sự khác biệt về hàm lượng vitmain $\mathrm{C}$, hàm lượng naringin $(\mathrm{p}<0,05)$, không có sự khác biệt về hàm lượng polyphenol $(\mathrm{p}>0,05)$. $\mathrm{pH} 4,5$ cho chế phẩm enzyme Biocitrus hoạt động tốt, dịch bưởi có hàm lượng naringin và vị đắng thấp, duy trì tốt các hợp chất vitamin $\mathrm{C}$ và polyphenol. Môi trường nước cam đạt pH 5 (Zhu et al., 2017), nước bưởi pH 4,5 5,0 (Ni et al., 2014), pH 4-6 (Busto et al., 2007) cho enzyme naringinase hoạt động hiệu quả. $\mathrm{pH} 4,5$ cho chế phẩm enzyme Biocitrus hoạt động hiệu quả trong môi trường nước bưởi. 


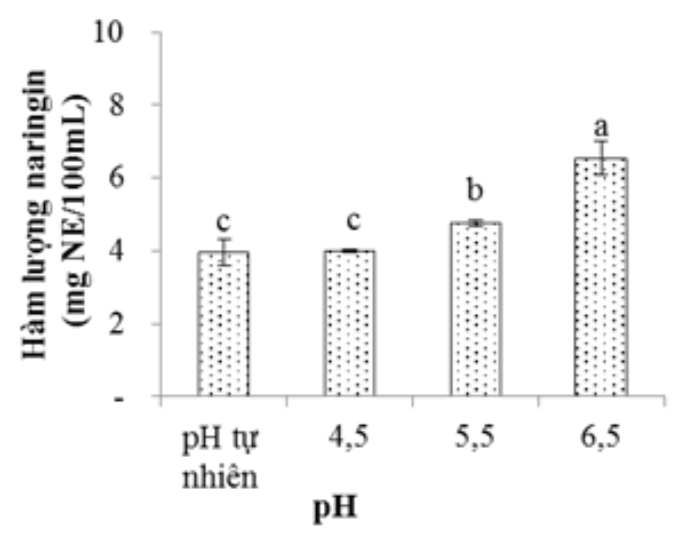

A

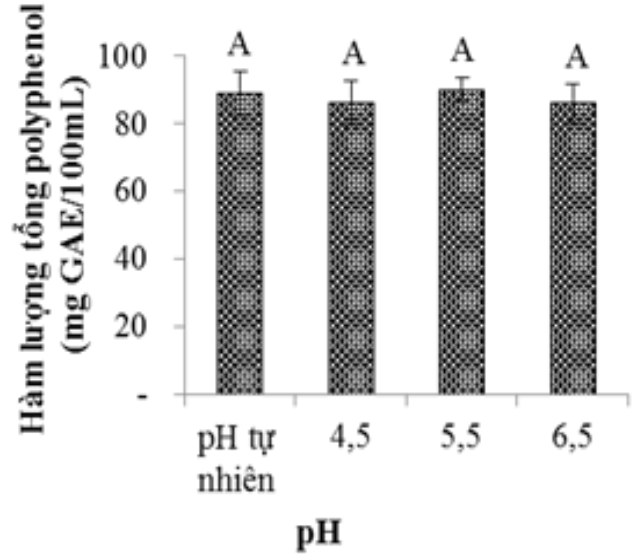

B

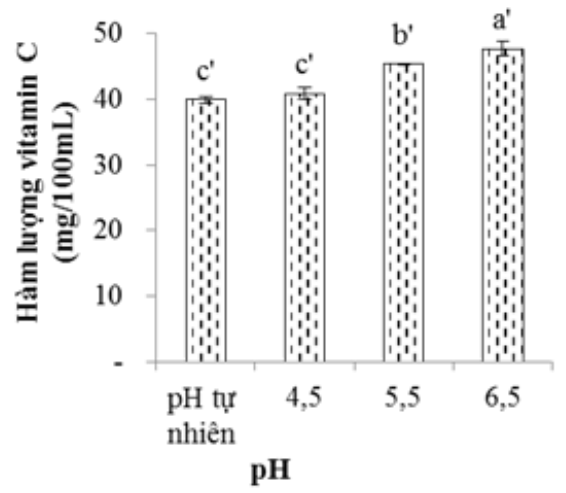

C

Hình 2. Ảnh hưởng của pH thủy phân đến biến đổi (A) hàm lượng naringin, (B) hàm lượng tổng polyphenol, $(\mathrm{C})$ hàm lượng vitamin $\mathrm{C}$

Các ki tụ khác nhau thể hiện sụ khác biệt thống kê giũua các giá trị ở độ tin cậy p<0,05. pH tụ nhiên (3,5-3,6)

3.2. Ảnh hưởng của nhiệt độ đến khả năng hoạt động của chế phẩm enzyme

Sự thay đổi về nhiệt độ đã thay đổi khả năng thủy phân của enzyme đối với hợp chất naringin (Hình 3). Mẫu có nhiệt độ thủy phân $50^{\circ} \mathrm{C}$ và $60^{\circ} \mathrm{C}$ có hàm lượng naringin thấp nhất là 3,26 và $3,6 \mathrm{mg} / 100 \mathrm{~g}$; kế tiếp là mẫu $40^{\circ} \mathrm{C}$ với $4,12 \mathrm{mg} / 100 \mathrm{~g}$ và mẫu nhiệt độ phòng $\left(29-31^{\circ} \mathrm{C}\right.$. Hàm lượng polyphenol tổng giữa các mẫu khác biệt khi thay đồi nhiệt độ thủy phân. Sự thay đổi này có xu hướng tăng dần khi tăng nhiệt độ thủy phân từ $30^{\circ} \mathrm{C}$ đến $60^{\circ} \mathrm{C}$, tương ứng với hàm lượng polyphenol tổng tăng từ 62,78 mgGAE/100mL lên 72,11 mgGAE/100 mL. Có sự khác biệt về hàm lượng vitamin $\mathrm{C}$ giữa các mẫu khi thay đổi nhiệt độ thủy phân; tuy nhiên sự khác biệt này là không có ý nghĩa thống kê. Hàm lượng Vitamin $\mathrm{C}$ ghi nhận được là 39,83 - 41,19 mgAAE/100 mL. Enzyme naringinase có khả năng thủy phân tốt naringin trong nước cam tại nhiệt độ $60^{\circ} \mathrm{C}$ (Yalim et al., 2004). Từ các kết quả đã phân tích, nhiệt độ $60^{\circ} \mathrm{C}$ được lựa chọn là kết quả thí nghiệm do khả năng giảm naringin tốt. 


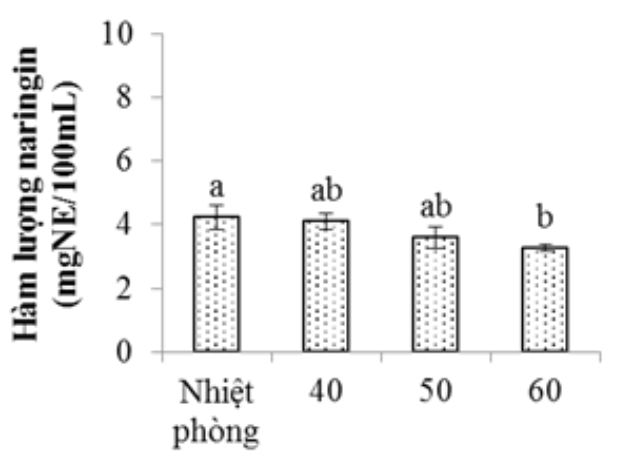

Nhiệt độ $\left({ }^{\circ} \mathrm{C}\right)$

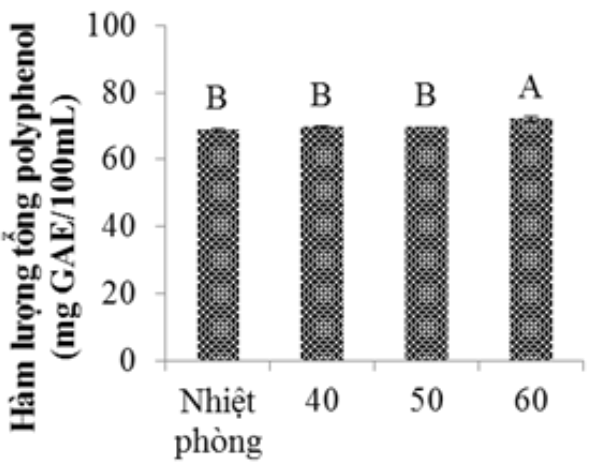

Nhiệt độ $\left({ }^{\circ} \mathrm{C}\right)$

A

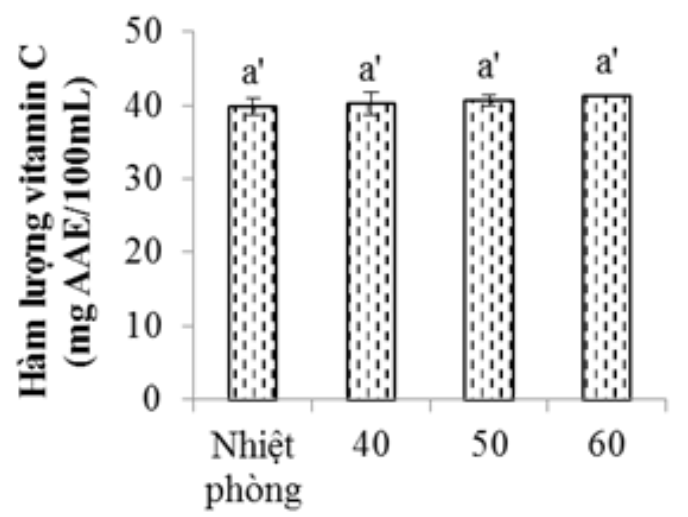

Nhiệt độ $\left({ }^{\circ} \mathrm{C}\right)$

C

Hình 3. Ảnh hưởng của nhiệt độ thủy phân đến biến đổi (A) hàm lượng naringin, (B) hàm lượng polyphenol tổng, $(\mathrm{C})$ hàm lượng vitamin $\mathrm{C}$

Các ki tư giống nhau thì không khác biệt thống kê giữa các giá trị ở độ tin cậy $p<0,05$, nhiệt độ phòng $\left(29-31^{\circ} \mathrm{C}\right)$,

\section{3. Ảnh hưởng thời gian thủy phân đến khả năng hoạt động của chế phẩm enzyme}

Kết quả thể hiện trong Hình 4 cho thấy thời gian thủy phân ảnh hưởng có thống kê đến sự biến đổi hàm lượng các hợp chất kháng oxy hóa của nước bưởi $(\mathrm{p}<0,05)$. Hàm lượng naringin giảm dần (từ 4,18 đến $3,76 \mathrm{mgNE} / 100 \mathrm{~mL}$ ) khi tăng thời gian thủy phân (từ 0,5 đến 3 giờ); trong đó mẫu thủy phân tại 2 giờ có hàm lượng naringin thấp nhất 35,1 mgNE/100mL. Tại mỗi thời gian thủy phân khác nhau, mẫu sau thủy phân có hàm lượng polyphenol khác nhau; tăng thời gian thủy phân (từ 0,5 đến 3 giờ) đã làm cho hàm lượng polyphenol tổng tăng (từ 76,97 đến 83,51 mg GAE/100g).
Mẫu thủy phân trên 3 giờ có hàm lượng viatamin C (39,27 mg AAE/100mL) cao hơn so với mẫu thủy phân tại 0,5 giờ $(37,89 \mathrm{mg} \mathrm{AAE} / 100 \mathrm{~mL})$. Khi thời gian thủy phân tăng, enzyme có đủ thời gian tiếp xúc với cơ chất và thực hiện các phản ứng phân giải. Nghiên cứu của Bodakowska-Boczniewicz et al. (2019) và Ribeiro and Ribeiro (2008) cho thấy quá trình thủy phân naringin trong nước bưởi chùm đạt hiệu quả cao khi thời gian thủy phân với enzyme naringinase trên 2 giờ. Thời gian thủy phân 2 giờ giúp tiết kiệm thời gian xử lý, duy trì tốt hàm lượng các hợp chất kháng oxy hóa cũng như hiệu quả tốt giảm hàm lượng naringin. 


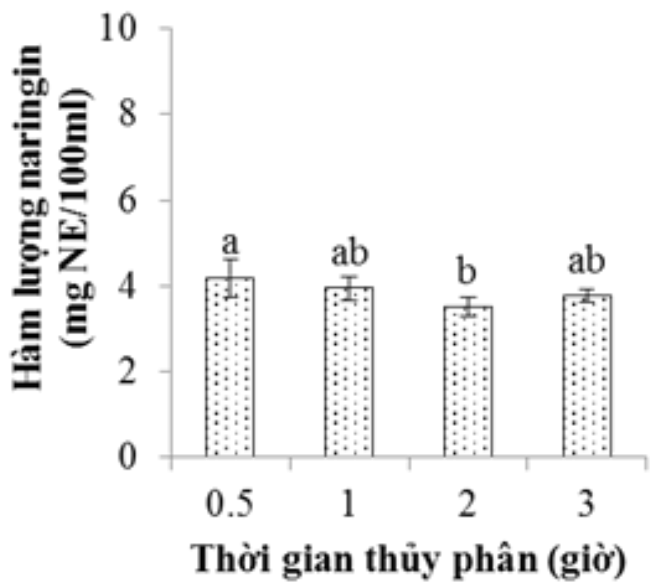

A

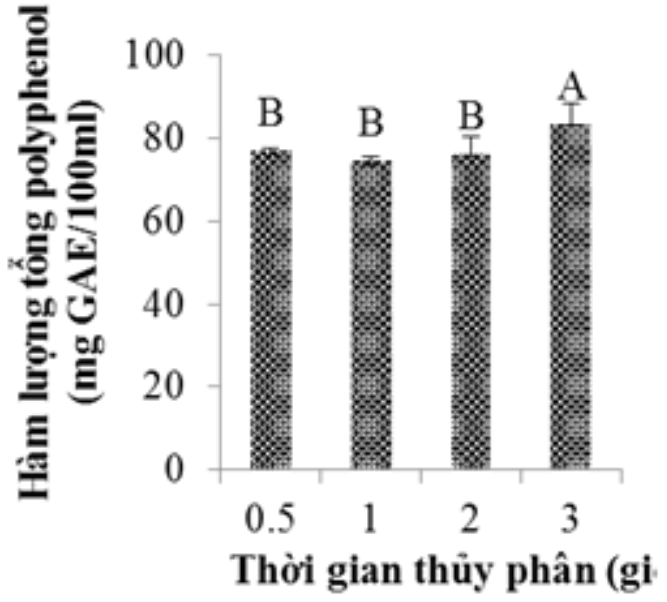

B

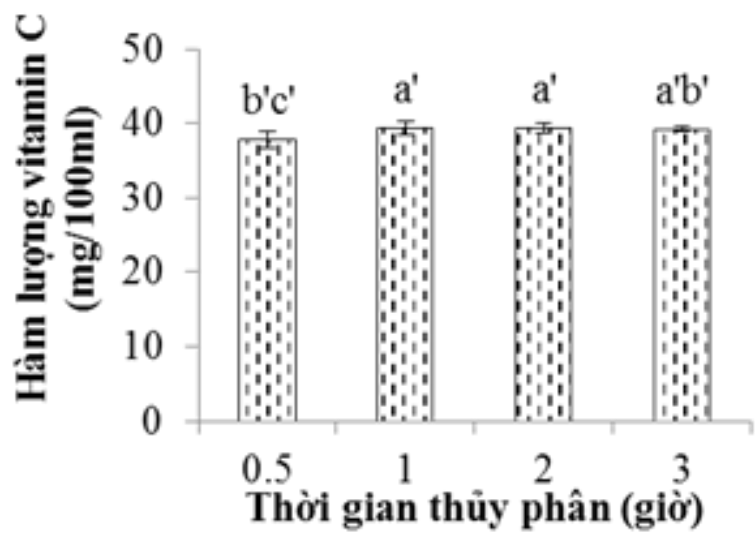

C

Hình 4. Ảnh hưởng của thời gian thủy phân đến biến đổi (A) hàm lượng naringin, (B) hàm lượng tổng polyphenol, $(\mathrm{C})$ hàm lượng vitamin $\mathrm{C}$

\subsection{So sánh thành phần hóa học và vị đắng của nước bưởi có và không xử lý enzyme}

Hàm lượng các hợp chất kháng oxy hóa và cường độ vị đắng giữa mẫu có xử lý enzyme và không enzyme là có sự khác biệt rõ rệt và có ý nghĩa thống kê (Hình 5). Mẫu không xử lý enzyme có điểm cường độ vị đắng là 7 ; biểu thị cho mẫu đắng và đắng nhiều; trong khi đó mẫu xử lý enzyme có vị đắng nhẹ; với số điểm là 3 . Mẫu xử lý enzyme có hàm lượng naringin giảm 47\%, polyphenol tổng tăng $13 \%$ và vitamin $C$ tăng $5 \%$ so với mẫu không xử lý. Một số nghiên cứu trước đó cũng cho thấy sử dụng enzyme naringinase có hiệu quả tốt trong giảm hàm lượng naringin trong nước bưởi chùm. Nghiên cứu của Mishra and Kar (2003) cho thấy sử dụng enzyme nariginase cố định bằng calcium alginate, với điều kiện thủy phân $55^{\circ} \mathrm{C} / 3$ giờ, giảm $84 \%$ naringin trong nước bưởi chùm; nghiên cứu Ribeiro and Ribeiro (2008) sử dụng enzyme naringinase cố định bằng $\kappa$-carrageenan giảm $65 \%$ naringin trong nước bưởi chùm. Lei et al. (2011), giảm 96,09\% naringin; Huang et al. (2017) giảm 22,7\% naringin bằng enzyme cố định bởi cellulose acetate nanofibers; Ni et al. (2014) kết hợp 5U/g enzyme pactinase và $0,4 \mathrm{U} / \mathrm{g}$ naringinase trong 60 phút giảm hàm lượng naringin từ $338 \mu \mathrm{g} / \mathrm{mL}$ xuống 42.4 $\mu \mathrm{g} / \mathrm{mL}$. Như vậy, xử lý dịch bưởi với chế phẩm enzyme Biocitrus đã giúp làm giảm vị đắng của sản phẩm sau thanh trùng. 


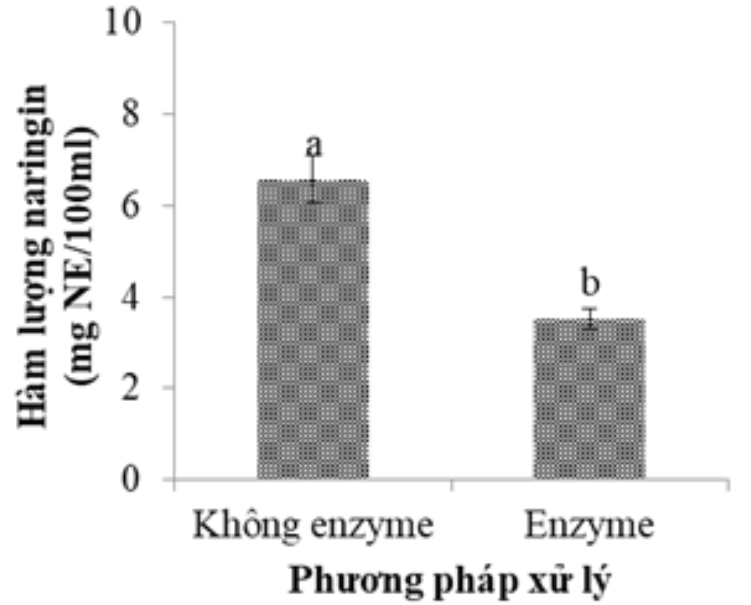

A

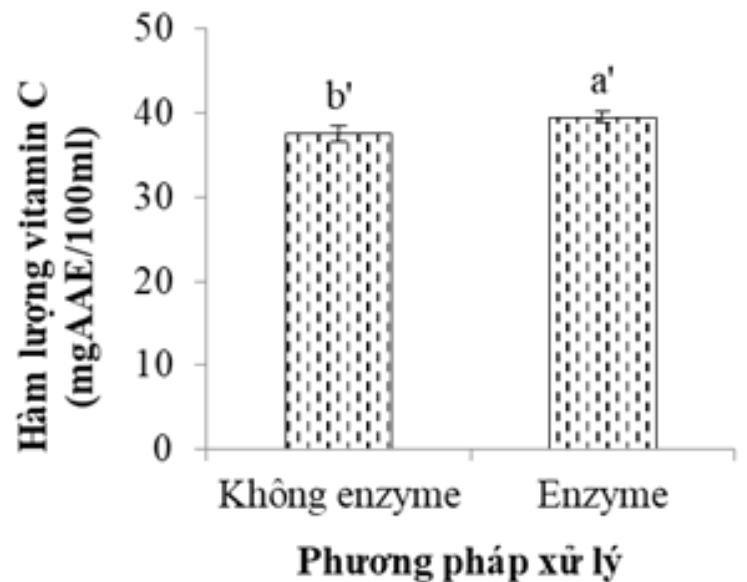

C

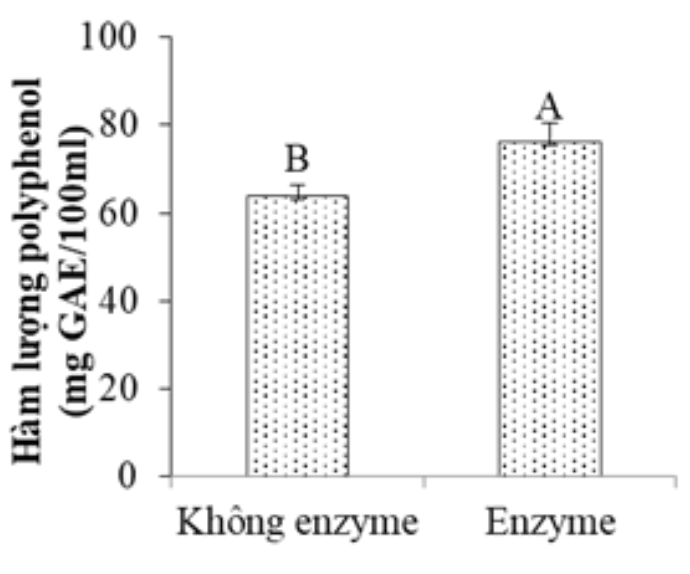

\section{Phương pháp xữ lý}

B

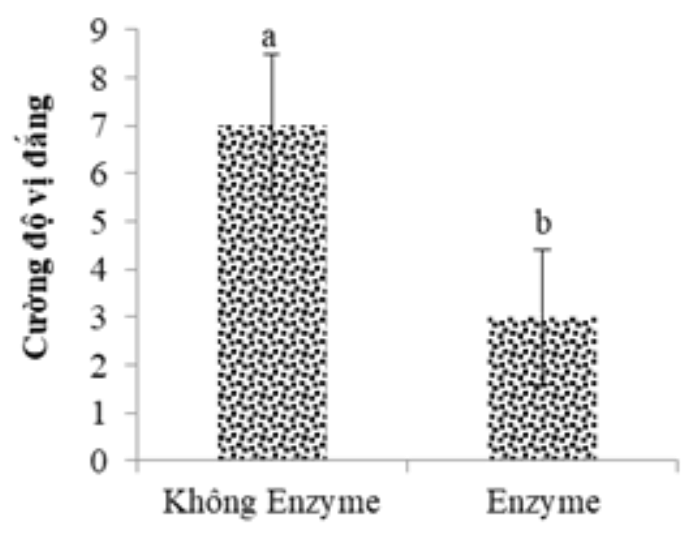

D

Hình 5. (A) Hàm lượng naringin, $(B)$ hàm lượng tổng polyphenol, $(C)$ hàm lượng vitamin $C$, và $(\mathrm{D})$ cường độ vị đắng của nước bưởi thanh trùng có và không xử lý giảm đắng

\section{KÊT LUẬN}

Nước ép bưởi được xử lý với chế phẩm enzyme Biocitrus có vị đắng ít hơn so với nước bưởi sau thanh trùng so với mẫu không xử lý. Gia tăng nhiệt độ $\left(30-60^{\circ} \mathrm{C}\right)$ và thời gian thủy $(0,5-2,0$ giờ $)$, giảm độ $\mathrm{pH}$ của nước ép bưởi $(6,5-3,5)$ đã làm giảm hàm lượng naringin có trong nước bưởi. Nước ép bưởi được xử lý giảm đắng với xúc tác của enzyme Biocitrus ở điều kiện nhiệt độ $60^{\circ} \mathrm{C}, \mathrm{pH} 4,5$ trong thời gian 2 giờ cho sản phẩm sau thanh trùng có vị đắng nhẹ, duy trì tốt hàm lượng polyphenol cũng như vitamin $\mathrm{C}$. Để tìm ra được thông số tối ưu cho quá trình thủy phân giảm đắng của nước bưởi thanh trùng, cũng như đánh giá được sự tương tác giữa các yếu tố $\mathrm{pH}$, nhiệt độ, thời gian thủy phân đến khả năng hoạt động của enzyme Biocitrus, thí nghiệm tối ưu hóa cần được thực hiện trong nghiên cứu tiếp theo.

\section{LỜI CẢM TẠ}

Nghiên cứu này được tài trợ kinh phí từ Sở Khoa học và Công nghệ Thành phố Hồ Chí Minh (40/2018/HĐ-QKHCN).

\section{TÀI LIỆU THAM KHẢO}

Bodakowska-Boczniewicz, J., \& Garncarek, Z. (2019). Immobilization of Naringinase from Penicillium decumbens on Chitosan Microspheres for Debittering Grapefruit Juice. Molecules, 24(23), 4234. https://doi.org/10.3390/molecules24234234

Busto, M. D., Meza, V., Ortega, N., \& Perez-Mateos, M. (2007). Immobilization of naringinase from 
Aspergillus niger CECT 2088 in poly (vinyl alcohol) cryogels for the debittering of juices. Food Chemistry, 104(3), 1177-1182. https://doi.org/10.1016/j.foodchem.2007.01.033

Cheong, M. W., Liu, S. Q., Zhou, W., Curran, P., \& $\mathrm{Yu}$, B. (2012). Chemical composition and sensory profile of pomelo (Citrus grandis (L.) Osbeck) juice. Food Chemistry, 135(4), 2505-2513. https://doi.org/10.1016/j.foodchem.2012.07.012

Davis, W. B. (1947). Determination of Flavanones in Citrus Fruits. Analytical Chemistry, 19(7), 476478. https://doi.org/10.1021/ac60007a016

De Silva, G. O., Marapana, R. A. U. J., \& Manawaduge, R. (2017). Effect of naringinase enzymatic treatment on the bitter compound naringin in fresh juice of" Bibila sweet" oranges. Joumal of Pharmacognosy and Phytochemistry, 6(4), 174-178.

Hà Duyên Tư. (2010). Kỹ thuật phân tích cảm quan thực phẩm. Nhà xuất bản Khoa học và Kỹ thuật.

Huang, W., Zhan, Y., Shi, X., Chen, J., Deng, H., \& Du, Y. (2017). Controllable immobilization of naringinase on electrospun cellulose acetate nanofibers and their application to juice debittering. International Journal of Biological Macromolecules, 98, 630-636. https://doi.org/10.1016/j.ijbiomac.2017.02.018

Kapur, A., Hasković, A., Čopra-Janićijević, A., Klepo, L., Topčagić, A., Tahirović, I., \& Sofić, E. (2012). Spectrophotometric analysis of total ascorbic acid content in various fruits and vegetables. Bulletin of the Chemists and Technologists of Bosnia and Herzegovina, 38(4), 39-42.

Lei, S., Xu, Y., Fan, G., Xiao, M., \& Pan, S. (2011). Immobilization of naringinase on mesoporous molecular sieve MCM-41 and its application to debittering of white grapefruit. Applied Surface Science, 257(9), 4096-4099. https://doi.org/10.1016/j.apsusc.2010.12.003.

Lim, Y. Y., Lim, T. T., \& Tee, J. J. (2007). Antioxidant properties of several tropical fruits: A Comparative study. Food Chemistry, 103(3), 1003-1008. https://doi.org/10.1016/j.foodchem.2006.08.038

Mishra P. \& Kar R. (2003). Treatment of Grapefruit Juice for Bitterness Removal by Amberlite IR 120 and Amberlite IR 400 and Alginate Entrapped Naringinase Enzyme. Journal of Food Science, 68(4), 1229-1233. https://doi.org/10.1111/j.1365-

2621.2003.tb09630.x

Ni, H., Yang, Y.F., Chen F., Ji H.F., Yang H., Ling W., \& Cai H.N. (2014). Pectinase and naringinase help to improve juice production and quality from pummelo (Citrus grandis) fruit. Food Science and Biotechnology, 23, 739746. https://doi.org/10.1007/s10068-014-0100-x

Patil, M. B. \& Dhake, A. B. (2014). Debittering of citrus fruit juice by naringinase of Penicillium purpurogenum. International journal of Engineering Research and Science and Technology, 3(2), 266-270.

Prakash, S., Singhal, R. S., \& Kulkarni, P. R. (2002). Enzymic debittering of Indian grapefruit (Citrus paradisi) juice. Journal of the Science of Food and Agriculture, 82, 394-397. https://doi.org/10.1002/jsfa.1059

Ribeiro, I. A. C. \& Ribeiro, M. H. L. (2008). Kinetic modelling of naringin hydrolysis using a bitter sweet alfa-rhamnopyranosidase immobilized in k-carrageenan. Journal of Molecular Catalysis B: Enzymatic, 51(1-2), 10-18. https://doi.org/10.1016/j.molcatb.2007.09.023

Toh, J. J., Khoo, H. E., \& Azrina, A. (2013). Comparison of antioxidant properties of pomelo (Citrus Grandis (L) Osbeck) varieties. International Food Research Journal, 20(4), 1661-1668.

Xu, G., Liu, D., Chen, J., Ye, X., Ma, Y., \& Shi, J. (2008). Juice components and antioxidant capacity of citrus varieties cultivated in China. Food chemistry, 106(2), 545-551. https://doi.org/10.1016/j.foodchem.2007.06.046

Yadav, V., Yadav, P. K., Yadav, S., \& Yadav, K. D. S. (2010). $\alpha$-L-Rhamnosidase: a review. Process Biochemistry, 45(8), 1226-1235. https://doi.org/10.1016/j.procbio.2010.05.025

Yalim, S., Özdemir, Y., \& Ekiz, H. İ. (2004). Naringin in Turkish orange juices and its reduction by naringinase. Journal of Food and Drug Analysis, 12(3), 273-276. https://doi.org/10.38212/2224-6614.2642

Zhu, Y., Jia, H., Xi, M., Li, J., Yang, L., \& Li, X. (2017). Characterization of a naringinase from Aspergillus oryzae 11250 and its application in the debitterization of orange juice. Process Biochemistry, 62, 114-121. https://doi.org/10.1016/j.procbio.2017.07.012 